Measures and the great work it has accomplished during the past twenty-five years. Nothing is said about the International Prototype units of length and mass, which are the real standards of the world to-day, and it is implied that the meter and kilogramme are, except for practical purposes, what they were defined to be a hundred years ago. The ratios of the metric to our customary units used, in the book, are not those legally adopted by the U. S.Office of Weights and Measures, but the differences are so small that the conversion tables are not sensibly in error. There is a growing use of the metric system in this country, the result of an increasing trade with foreign countries, and this book will satisfy every demand of those who are called upon to convert from one system to the other. The tables are so numerous that it is difficult to imagine a call for anything which the book does not contain, and a convenient index renders them quickly available. Much time is saved by carrying the tables up to one-hundred multiples of each unit, but in a few instances space and labor have been wasted in doing this, because of the impossibility of such conditions ever being realized. For instance, in the table for converting ' grammes in a cubic centimeter to ounces in a cubic inch,' there does not appear to be any necessity for going beyond 23 or 24 as there is no known substance denser than this. Thus more than three-quarters of this table can be of no use, and this is true of several tables of a similar character. On the whole the work is exceedingly well done, and the book ought to be much sought after.

T. C. M.

\section{THE ELECTROLYTIC INTERRUPTER FOR THE INDUCTION COIL.}

WHEN a high electro-motive force is connected to an electrolytic cell, one electrode of which is very small, the rush of current which takes place is quickly interrupted by the layer of gas which is generated at the small electrode. This layer of gas then collects as a bubble, the electrolyte again comes into contact with the electrode, a rush of current again takes place to be interrupted as before, and so on. These interruptions are very abrupt, and their frequency varies from two or three hundred to a thousand or more per second according to the size of the small electrode and the inductance of the circuit. The small electrode should be the anode.

Dr. A. Wehnelt (Electrical Engineer, February $16,1899)$ has applied this electrolytic interrupter to the induction coil. He uses dilute sulphuric acid, a sheet of lead as cathode, and the tip of a small platinum wire projecting from a glass tube as anode. The interrupter works with entire satisfaction with electro-motive forces as high as 110 volts; the condenser, needed with the ordinary interrupter, is useless; and the effectiveness, especially of small coils, is greatly increased both in length of spark and frequency.

Dr. Wehnelt's experiments have been repeated in the Physical Laboratory at Bethlehem Pa., his results have been confirmed, and it has been found that the primary of an induction coil should be wound with more turns of wire than usual to give the best results with this electrolytic interrupter. The interrupter gives good effects when used to supply intermittent current to the primary of a small transformer. Thus a small step-down transformer taking 375 watts from the mains gave out about 30 watts from its secondary.

When the electrolytic interrupter is used to supply intermittent current from a 110 volt source to the primary of a transformer, the e. m. f. which establishes the current after each break is, of course, 110 volts, while the e. m. f. which stops the current is the e. m. f. between the break points and may be very greatly in excess of 110 volts.

The effective primary e. m. f. is, therefore, on the whole, greatly in excess of 110 volts, so that a 1:1 transformer may give several hundreds of volts at its secondary terminals when supplied with intermittent current from a 110 volt source.

This is shown by the fact that a 220 volt lamp, for example, may be lighted from the secondary, and, of course, it may be lighted equally well or even better if connected across the primary terminals.

W. S. F.

$$
\begin{aligned}
& \text { THE RESISTANCE OF CARBON AND COPPER } \\
& \text { BRUSHES. }
\end{aligned}
$$

Professor E. Arnold gives, in the Electrical Zeitschrift for January 5th, a study of the 'Con- 